\title{
Preface: Climate change and wetlands in Australia
}

\author{
C. Max Finlayson
}

Received: 15 November 2012/Accepted: 24 November 2012/Published online: 14 December 2012

(C) Springer Science+Business Media Dordrecht 2012

The genesis of this special issue came from the participation of many of the authors in the Wetland Ecosystems session held during the 3rd International Conference on Challenges in Environmental Science and Engineering, CESE-2010, 26th September-1st October 2010, Cairns, Australia. The speakers and authors are thanked for their contributions. Mr George Lukacs, a co-Chair of the Conference and from the Australian Centre for Tropical Freshwater Research James Cook University, is thanked for issuing the invitation to hold this session and for arranging support for the speakers.

The special issue contains papers that cover some of the expected impacts of climate change on Australian wetlands. They cover the following topics: assessment of wetlands under climate change; adaptation and engineering responses to climate change; and restoring wetlands under a changing climate. The key issues from these papers have wider application for the wise use of wetlands elsewhere especially where there are biogeographical similarities or common approaches for wetland management.

Guest editor: C. Max Finlayson / Wetlands and climate change: ecological outcomes and adaptation as shown by Australian case studies

C. M. Finlayson $(\bowtie)$

Institute for Land, Water \& Society, Charles Sturt

University, Albury, NSW 2640, Australia

e-mail: mfinlayson@csu.edu.au
Information from the individual papers can also contribute to efforts underway through the Ramsar Convention on Wetlands to develop new guidance for wetland managers as part of its widely accessed Handbooks for the Wise Use of Wetlands. The Convention has been at the forefront of global efforts to maintain and restore the ecological character of wetlands with the adoption in 1971 of the prescient concept of wise use. This concept has a lot in common with the later concepts of sustainable development and ecosystem approaches for integrated environmental management. Whilst variously seen as a biodiversity treaty, the Convention has long supported the concept of wise use of wetlands alongside the more traditional conservation approaches that we have witnessed for much of the past 40-50 years.

Further, the Convention has been at the forefront of efforts to ensure that the wider values and benefits obtained from wetlands are maintained and restored, where applicable. This was reflected in 2005 with the inclusion of ecosystem services within its central concept of ecological character. This was a direct outcome of having engaged with the Millennium Ecosystem Assessment (see www.millenniumassess ment.org), but also reflected a long term effort to bring people and wetlands together; an effort that has been subject to many reverses as well as advances. In doing this, it has created a large amount of policy and technical guidance for the use of its contracting parties, local communities, technical experts and wetland managers. 
The papers in this special issue focus on the scientific aspects of wetland management and include background information and guidance for wetland researchers and managers, and by implication, for policy makers. The topics covered include: (i) assessing changes in the distribution of wetland species and whether these constitute a change in the ecological character of the wetland; (ii) assessing the usefulness of models of wetland response to climate change; (iii) assessing the value in allocating water to protected sites where restoration would be contingent on reallocation of larger volumes of water; (iv) assessing the efficacy of engineering responses with the potential to deliver more water-efficient environmental outcomes for wetlands; and (v) determining if the description of the ecological character of a Ramsar site at the time of listing is a suitable reference for management purposes.

It is recommended that further attention is directed towards determining and responding to the ecological consequences of climate change and that this is integrated with wider management initiatives at both a landscape and site level. At a policy level, it provides information that supports the long-running efforts of the Convention to bring the issues associated with climate change and wetlands to the attention of the world's governments - an effort that has also seen as many reverses as advances. In this instance, we have been able to add to the science base for addressing wetlands and climate change, and provide a basis for further policy development.

The authors of the papers are thanked for their efforts. They have signalled that they have an understanding of the complex issues of dealing with wetlands and climate change, and, through their papers, have provided an invaluable information resource for researchers and others. 